\title{
CHEST LEADS FOR THE DEMONSTRATION OF AURICULAR ACTIVITY
}

\author{
BY \\ P. SZEKELY \\ From the Cardiovascular Department, Newcastle General Hospital, Newcastle on Tyne
}

Received September 25, 1944

In certain forms of disorder of rhythm, the correct electrocardiographic diagnosis depends to a great extent on the proper demonstration and interpretation of the activity of the auricles. This is especially the case in paroxysmal tachycardia. However, it is often very difficult with the usual leads to identify the auricular wave and to ascertain its relation to the ventricular deflection, because it may be very small and obscured by the QRS complex or the T wave. Attempts have been made, therefore, to devise special leads in order to obtain large auricular deflections. In this respect, the œsophageal lead (Brown, 1936; Deglaude and Laubry, 1939) is undoubtedly the best method at present, but in view of the hardship it imposes on the patient it can only be used in selected cases and certainly not in routine clinical cardiography. The purpose of this paper is to assess the value of special chest leads employed in this department during the last year in a number of cases, which were under the care of Professor Hume, upon the assumption that they would show auricular waves to much better advantage than the routine leads. I first became interested in this problem in 1940 during my visits to the Cardiac Department of the London Hospital. Dr. William Evans showed me how clearly the auricular waves in various arrhythmias were demonstrated in chest leads and called my attention to this method of investigation.

Lewis (1910) was the first to use special chest leads to facilitate the study of auricular waves. He noticed in cases of auricular fibrillation that the auricular oscillations were maximal when the electrodes were placed over the right auricle. He pointed out that the chest leads as used by him were especially helpful in cases with an enlarged right auricle, for in these cases a larger area of the auricular wall was in apposition to the chest wall. Drury and Iliescu (1921) found that coarse auricular oscillations in auricular fibrillation were more continuously present in the chest leads than in the limb leads. They used two chest leads, sternal and antero-posterior, for the demonstration of auricular activity. In the sternal lead, one electrode at the junction of the second right rib with the sternum was paired with another over the seventh right costal cartilage; in the antero-posterior lead, one electrode was placed on the centre of the sternum, and the other on the back at the level of the inferior angle of the scapula, two inches to the right of the vertebral column. Holzman (1937) observed that the largest auricular deflections in the chest leads occurred when the exploring electrode was placed to the right of the sternum. Lian and Pinchenzon (1938) studied the auricular rhythm in the "precordial auricular lead S 5": in this lead, one electrode over the manubrium sterni was paired with another in the fifth right intercostal space. Schoenewald (1939) was able to obtain clearer P waves than those in lead II, by leading off from the right border of the sternum, at the level of the third intercostal space, to the right arm. Evans (1941) studied the auricular activity in lead $\mathrm{CR}_{1}$ in 60 cases of auricular fibrillation, and showed that in many instances the auricular oscillations 
were the most conspicuous in this lead. He failed to notice any close relationship between the size of the right auricle and the amplitude of the $P$ waves. Williams and Ellis (1943) used special auricular precordial leads in their study of ventricular tachycardia: they placed the exploring electrode in the third intercostal space at the right sternal border, using first the right arm and then the left leg for the indifferent electrode; they stated that these leads have repeatedly clarified an otherwise doubtful diagnosis. Barker et al. (1943) suggested that in cases in which the $\mathbf{P}$ waves are small or indistinct in the standard leads, chest leads might prove helpful; in their opinion, by leading from two precordial contacts, one over the upper part of the sternum and the other over the ensiform process, it is usually possible to record large auricular waves.

\section{MethOD AND MATERIAL}

The method of taking special chest leads was that adopted by Schoenewald (1939), Faulkner (1943), and Williams and Ellis (1943). A circular electrode, $1.8 \mathrm{~cm}$. in diameter, was used as exploring electrode and was placed in the third intercostal space at the right sternal border. The indifferent electrode was placed either on the right arm (to be referred to in this paper as auricular lead R) or on the left leg (auricular lead F). In several instances both leads were recorded. Except in a few cases, in the initial stage of our study, in which auricular lead $F$ was recorded in reversed polarity for the sake of convenience, both auricular leads $\mathrm{R}$ and $\mathrm{F}$ and lead IV $\mathrm{R}$ were obtained in a manner corresponding closely to the recommendations of the Cardiac Society of Great Britain and Ireland and the American Heart Association (1939) i.e. the galvanometer connections were so arranged that relative positivity of the exploring electrode yielded an upward deflection on the finished curve. For the sake of conformity the few tracings originally recorded in reversed polarity and included in the analysis of this study have been reversed photographically. At first, auricular chest leads were recorded only in cases of paroxysmal tachycardia; but later their use was extended to other forms of arrhythmia and also to a number of cases showing sinus rhythm. Though the majority of the tracings showing sinus rhythm were in other respects abnormal and only a few normal cardiograms were available for comparative purposes, it was thought advantageous to include in this paper all available cases showing normal auricular rhythm.

\section{PAROXYSMAL TACHYCARDIA}

Ten cases were studied. In six, the auricular leads were regarded as helpful, in two cases they were of doubtful value, and in two cases they did not facilitate the reading of the tracings. In all six cases regarded as successful, there were clear $P$ waves in at least one of the auricular leads; while the standard leads and lead IV $R$ usually showed less distinct $P$ waves. The cardiograms of these six cases are reproduced in Fig. 1-7. One of the two cases in which the auricular leads were considered to be of doubtful value was very probably ventricular tachycardia at a rate of 212 a minute. The ventricular complex was broad $(0 \cdot 12 \mathrm{sec}$.), and there was slurring near the base of the $R$ wave in every second complex in the limb leads and in auricular lead F. The other case appeared to be auricular tachycardia at the rate of 180 a minute. The $P$ waves seemed to be obscured by the $T$ waves in all leads, but the configuration of the $S-T$ segment and the $T$ wave in both auricular leads $R$ and $F$ suggested the presence of a $\mathrm{P}$ wave much more strongly than did any of the standard leads. The two unsuccessful cases were thought to be auricular tachycardia. The $P$ waves appeared to be obscured by the $\mathrm{T}$ waves and they were not identified with certainty in any of the recorded leads.

The cardiograms reproduced in Fig. 1 are those of a man, aged 63 years, who has had attacks of palpitation for the past four years. He was admitted to hospital for observation on July 7, 1943, and during his five weeks' stay he had several attacks which proved to 


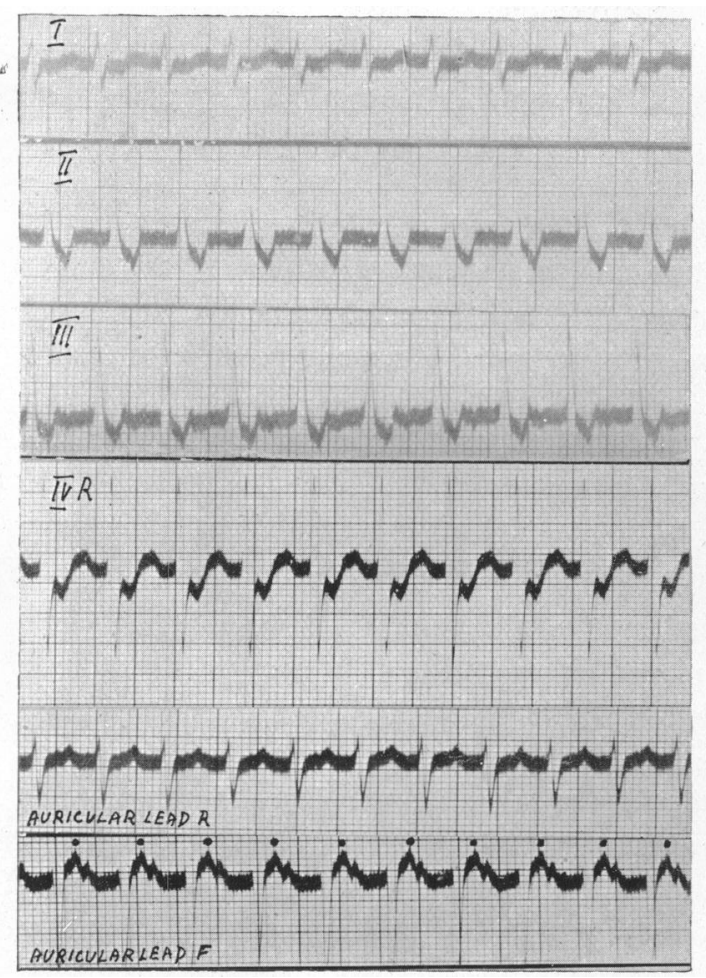

A

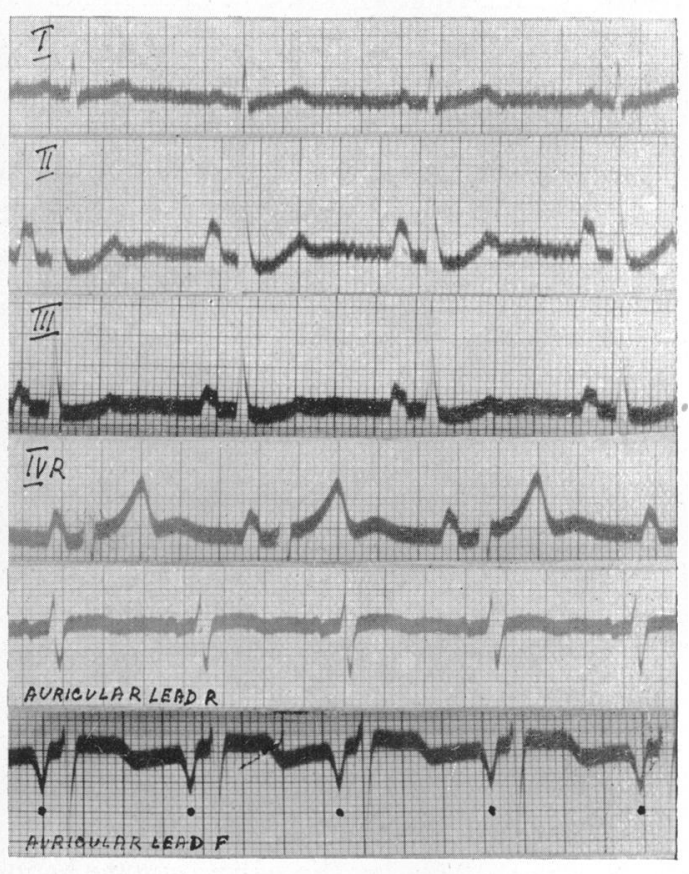

B

FIG. 1.-Case 1 (A). Nodal tachycardia at 176 a minute. Distinct $P$ waves can be seen in auricular lead $F$. In this and subsequent figures dots denote the sites of the $\mathbf{P}$ waves in the auricular leads.

(B). Sinus rhythm. Note the large $\mathbf{P}$ waves in auricular lead $F$.

be paroxysms of supraventricular, probably nodal, tachycardia. No underlying structural disease was found in the heart. Fig. 1A shows such an attack at a rate of 176 a minute. There are no visible $\mathbf{P}$ waves in lead $\mathrm{I}$. Though there is some suggestion of $\mathbf{P}$ waves in leads II and III, and also in IV R, auricular lead F is the lead in which $P$ waves are most distinctly shown. Auricular lead $R$ is similar to lead $I$ and shows no clear $P$ waves. Fig. 1B was taken a few days later after the tachycardia had stopped. It shows sinus rhythm with big $\mathbf{P}$ waves in lead II and in auricular lead F.

The cardiograms shown in Fig. 2 are those of a woman, aged 60 years, who had mitral stenosis and paroxysmal tachycardia. The first tracing shows auricular tachycardia at a rate of 166 a minute, with a $1: 1$ response. Auricular lead F appears to be the best lead for the demonstration of auricular activity. The second tracing, taken after digitalization, shows auricular tachycardia at the same rate as in the previous tracing, with a $2: 1 \mathrm{~A}-\mathrm{V}$ block. Here again, auricular lead $F$ shows the most conspicuous $P$ waves. Though the curves resemble auricular flutter, I decided eventually on paroxysmal tachycardia for the following reasons. (1) The rate (166 a minute) appeared to favour paroxysmal tachycardia. (2) The patient having been under observation for a long time before the tracings reproduced were taken had had numerous attacks of tachycardia, and in spite of practically continuous digitalization and massive doses of digitalis during some of the attacks, these attacks were apparently never converted into auricular fibrillation. Though clinically the rhythm was irregular at times and we thought it was auricular fibrillation, the available tracings showed distinct $P$ waves at regular intervals with irregular ventricular activity, and unequal .P-R intervals. The auricular deflections were separated by periods of electrical quiescence, thus making auricular flutter with variable block unlikely. I thought there were dropped beats or even A-V dissociation in one of the tracings. (3) Barker et al. (194) 

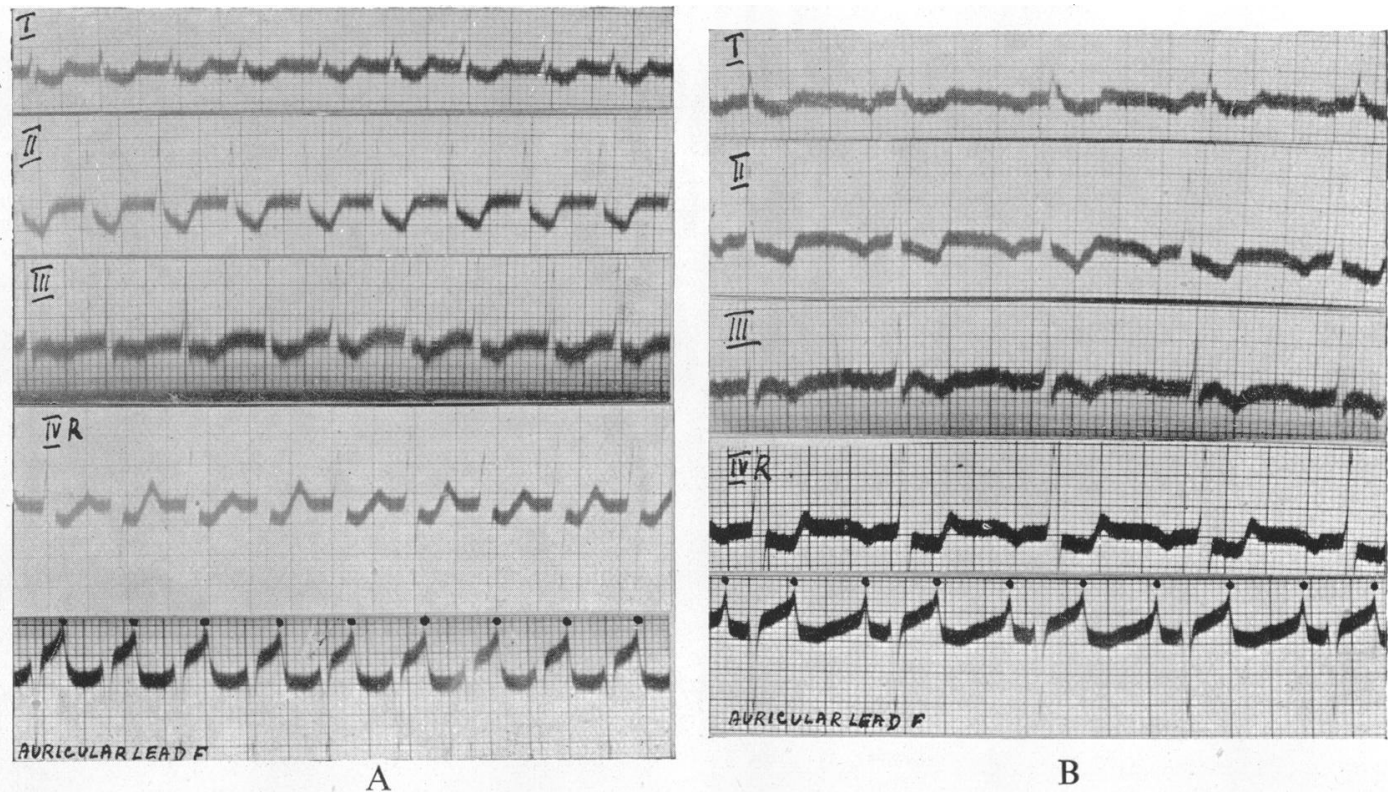

Fig. 2.-Case 2 (A). Probably auricular tachycardia with 1:1 response. Discussed in text. Rate 166 a minute. Clear, upright $\mathbf{P}$ waves in auricular lead $\mathrm{F}$.

(B). Probably auricular tachycardia with $2: 1 \mathrm{~A}-\mathrm{V}$ block. Discussed in text. Note the large $P$ waves in auricular lead $\mathrm{F}$.

reproduced tracings which they interpreted as auricular tachycardia and some of them appeared very similar to my tracings-Barker's Fig. 2B, on page 773, interpreted as auricular tachycardia with a $1: 1$ response, and Fig. 2C, same page, following digitalis, as auricular tachycardia with $2: 1 \mathrm{~A}-\mathrm{V}$ block. Fig. $6 \mathrm{~A}$, on page 778, is strikingly similar to my Fig. $2 \mathrm{~B}$. Barker's Fig. 13A also shows similar features.

The curve shown in Fig. 3 was obtained from a R.A.F. pilot, aged 20 years, who was admitted to hospital in an attack of tachycardia.* A similar attack six months previously had lasted for three days. The heart was normal in size on radioscopy, and apart from the tachycardia no abnormality could be detected. The cardiogram shows a tachycardia with a ventricular rate of about 160 a minute. The QRS complex is slightly widened but not grossly aberrant. Leads I and III are not suitable for the analysis of auricular activity. Leads II and IV R suggest $\mathbf{P}$ waves at a rate lower than that of the ventricles. Clear inverted $\mathbf{P}$ waves can be identified in auricular lead $\mathrm{F}$ at a rate of 100 a minute, so that the diagnosis of ventricular tachycardia seems to be justified.

The patient whose cardiogram is reproduced in Fig. 4, was a woman, aged 64 years, who had high blood pressure and heart failure. In the first lead the rhythm is irregular and no $\mathbf{P}$ waves can be identified, simulating auricular fibrillation. In lead II, the ventricular complexes are slightly irregular in time, the rate varying from 134 to 166 a minute; here, there is definite evidence of regular auricular activity at a rate of about 158 a minute. Lead III is similar to lead I as regards rhythm. In lead IV $R$ the ventricular rhythm is more or less regular, 158 a minute, and auricular waves cannot be identified with certainty. There is no clear evidence of auricular activity in auricular lead R. Auricular lead F shows clear, inverted $P$ waves at slightly irregular intervals, at a rate of about 158 a minute. This is probably a case of paroxysmal tachycardia with auriculor-ventricular dissociation, and with high auricular and ventricular rates.

The cardiogram shown in Fig. 5 is that of a man, aged 62 years, who was admitted to hospital in a desperate condition. The physical examination revealed a regular tachycardia. The patient died a few hours later, and autopsy showed a slight degree of coronary sclerosis,

* For this case I am indebted to Dr. George Davison. 


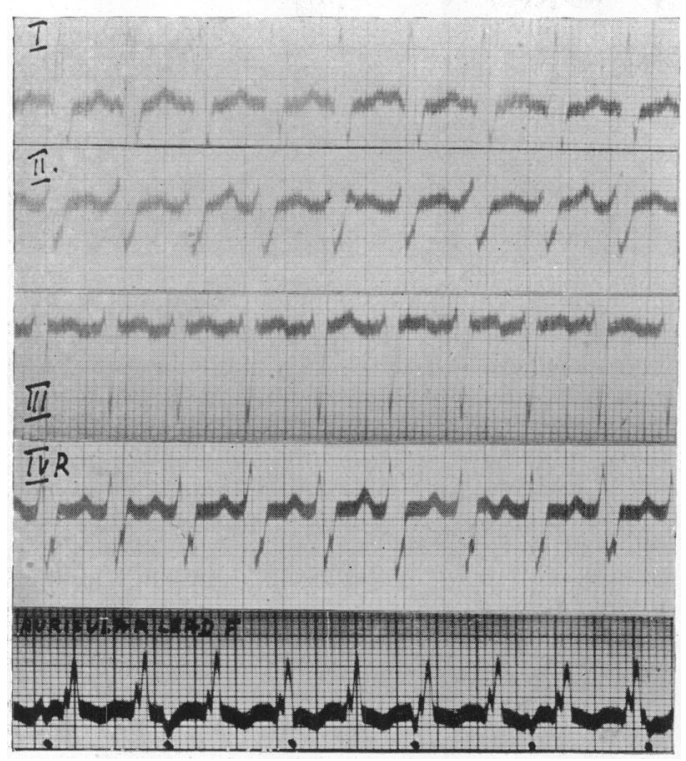

FIG. 3.-Case 3. Ventricular tachycardia. Ventricular rate 160 a minute, auricular rate 100 a minute. Clear, inverted $\mathbf{P}$ waves in auricular lead $\mathbf{F}$.

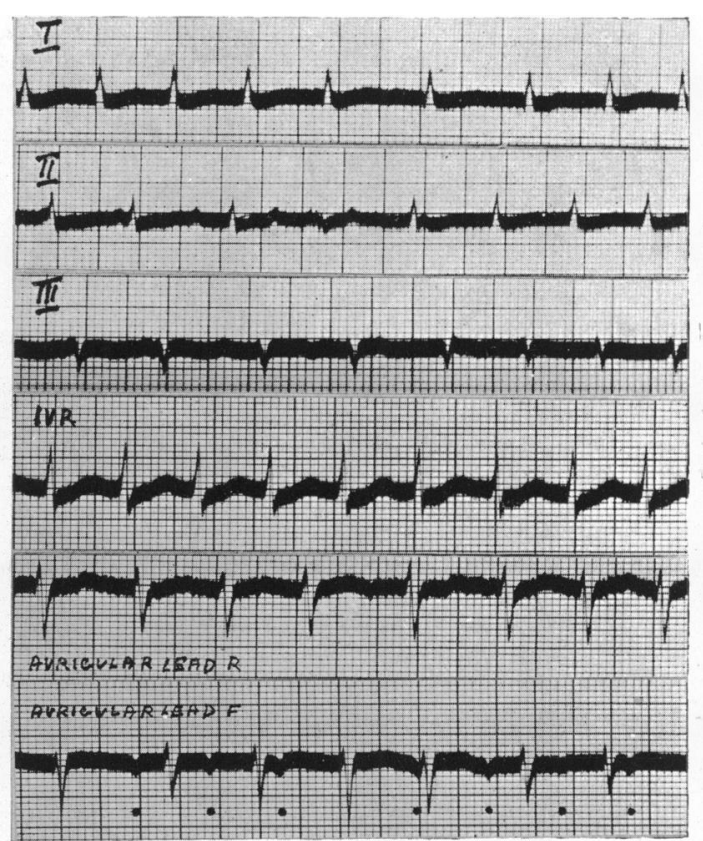

FIG. 4.-Case 4. A-V dissociation with high auricular and ventricular rates. Discussed in text. Distinct $\mathbf{P}$ waves are only seen in lead II and in auricular lead $F$.

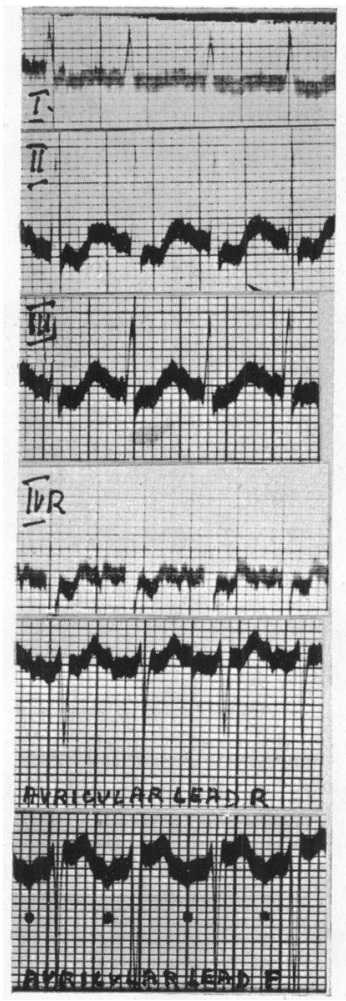

FIG. 5.-Case 5. Supraventricular tachycardia. Rate 170 a minute. Inverted $\mathbf{P}$ waves in auricular lead F.

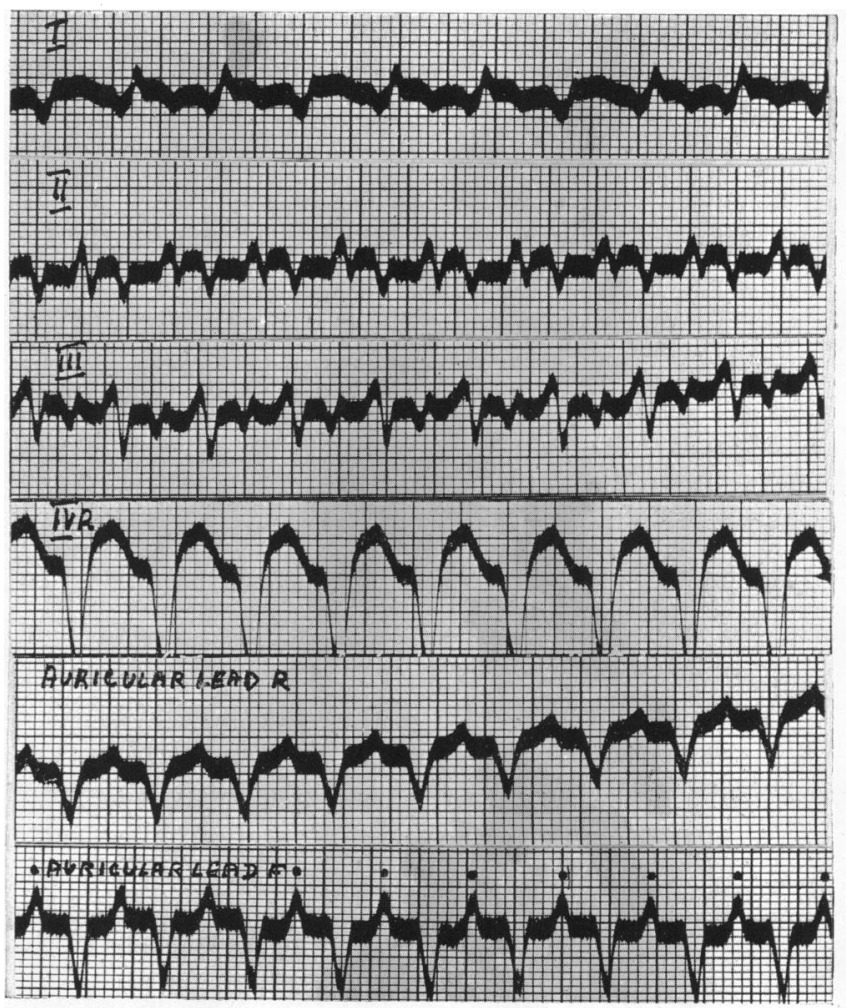

FIG. 6.-Case 6. Acute coronary artery occlusion. Tracing discussed in text. $\mathbf{P}$ waves are probably superimposed on T waves in auricular lead F. See also Fig. 7. 
but no cardiac enlargement and no gross myocardial fibrosis; there were extensive pleural adhesions on the left side and partial collapse of the left lung. The patient was very restless, making it impossible to get a steady record. It shows supraventricular tachycardia. Though the tracing is technically unsatisfactory, auricular lead $F$ shows the most distinct $P$ waves. They are inverted, at a rate of about 170 a minute, and can be clearly differentiated from the preceding $\mathrm{T}$ waves. Auricular lead $\mathbf{R}$ shows diphasic $\mathbf{P}$ waves at the same rate.

The cardiograms shown in Fig. 6 and 7 are those of a man, aged 67 years, who was admitted with occlusion of the coronary artery and paroxysmal tachycardia. The tracings are diagnostic of anterior myocardial infarction. Fig. 6 shows probably auricular tachycardia at a rate of 160 a minute. The $P$ waves in auricular lead $F$ are, we think, superimposed on the $T$ waves and probably this is the case in the other leads also. On the other hand, it is difficult to exclude flutter at the rate of 320 with a $2: 1$ response on this tracing alone. Fig. 7A, taken six days later after digitalization, shows auricular tachycardia at a rate of 150 a minute, with a $2: 1 \mathrm{~A}-\mathrm{V}$ block in the limb leads and Luciani-Wenckebach periods.

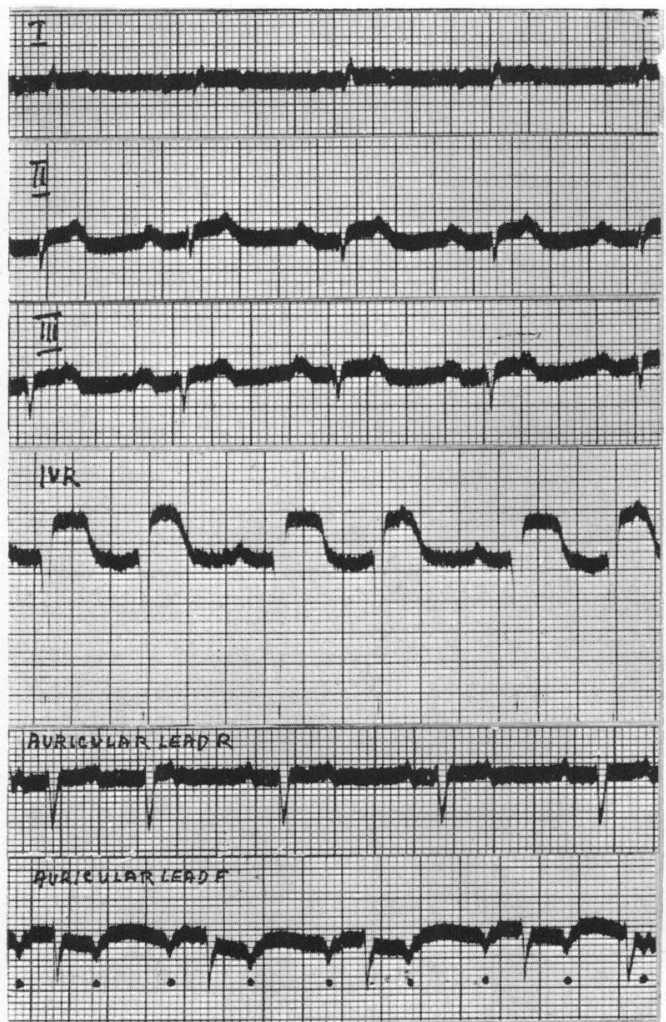

A
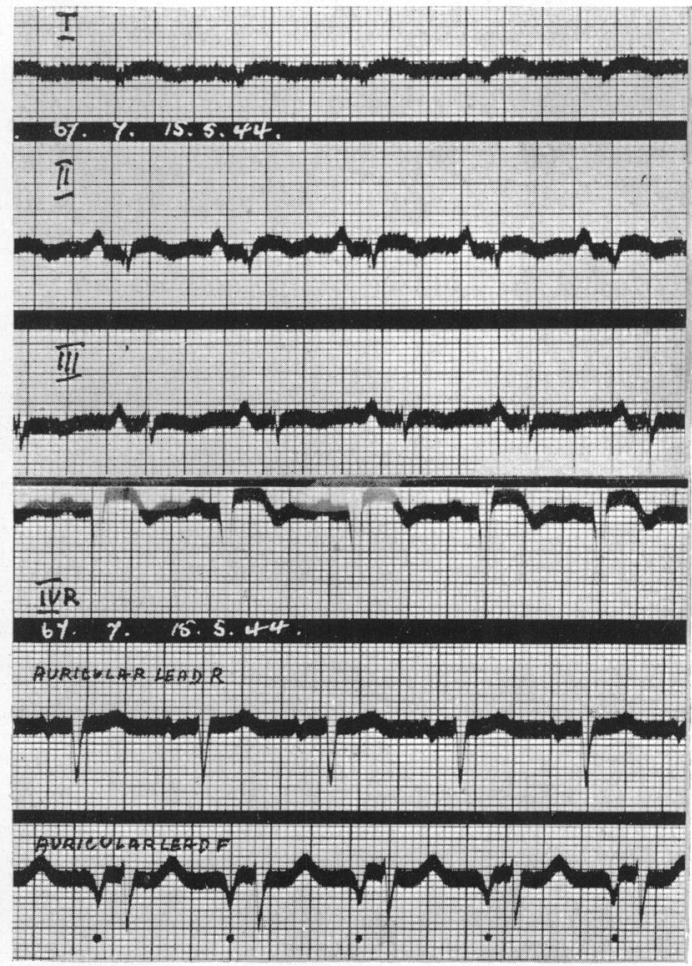

B

FIG. 7.-Case 6 (A). After digitalization. Auricular tachycardia at the rate of 150 a minute, with $2: 1$ A-V block in the limb leads and Luciani-Wenckebach periods at times in the chest leads. Inverted $\mathbf{P}$ waves in auricular lead $\mathrm{F}$.

(B). After discontinuation of digitalis for 23 days. Sinus rhythm with normal P-R interval. Here again, inverted $P$ waves in auricular lead $F$.

at times in the chest leads. Auricular lead $F$ shows conspicuous inverted $P$ waves. Fig. $7 \mathrm{~B}$, taken 23 days after discontinuation of digitalis, shows sinus rhythm with normal P-R interval, and auricular lead $\mathrm{F}$ shows deeply inverted $\mathrm{P}$ waves.

\section{Auricular Flutter and Fibrillation}

Only one case of undoubted flutter was studied. The cardiogram of this patient, a man, aged 35 years, with mitral stenosis, is reproduced in Fig. 8 (page 245). It shows a $2: 1$ auricular flutter with marked flutter waves in auricular lead F. 
Seven cases of auricular fibrillation were studied. In three of them the fibrillation waves were more conspicuous in the auricular leads than in the standard leads, while in the remaining four there was no appreciable difference.

\section{SINUS RHYTHM}

In addition to the cases of paroxysmal tachycardia in which tracings showing sinus rhythm were obtained after the paroxysm had stopped, 50 cases were available for study, and 60 cardiograms were taken. All but three were obtained from patients suffering from various forms of heart disease. It is not suggested that the auricular leads have any significant advantages over the standard leads in cases of normal auricular rhythm: nevertheless, a brief description of the form and amplitude of the $\mathrm{P}$ wave in the auricular leads may be of interest. Of the 60 cardiograms 15 included both auricular leads $R$ and $F$. In the remaining 45 only auricular lead $F$ was recorded. The $P$ wave in auricular lead $R$ was positive in 10 , and diphasic in 5 instances. Only in one instance was the $P$ wave in auricular lead $R$ greater in amplitude than in auricular lead F; in another both leads showed equal $P$ waves; and in 13 instances auricular lead $F$ showed more conspicuous $P$ waves than auricular lead $R$. A comparison of auricular lead $R$ with the standard leads revealed only one case in which the largest $\mathbf{P}$ waves occurred in auricular lead $\mathbf{R}$. In the remainder, at least one of the standard leads showed $\mathbf{P}$ waves either equal in amplitude to those in auricular lead $\mathbf{R}$ or even larger. The $P$ wave in auricular lead $F$ was upright in 3, diphasic in 6 , and inverted in 51 instances. Auricular lead $F$ was compared with the standard lead showing the largest $\mathbf{P}$ wave; and it was found that, judged by the amplitude of this wave, auricular lead $\mathrm{F}$ was superior to the standard lead in 19, equal to it in 16, and inferior in 25 instances.

\section{Discussion}

The special chest leads used in this study often display larger auricular waves than the standard leads, and thus help the interpretation of records showing abnormal rhythms. Auricular lead F appears to be superior to auricular lead R. Though Wood and Selzer (1939) stated that the right arm was the better distal electrode for the study of auricular activity, it is open to question whether their results can be directly compared with ours because they used a different technique, placing the exploring electrode in the fourth intercostal space at the right sternal border (leads $C_{1}$ and $C F_{1}$ ). In ten unselected cases we studied the $P$ waves in both auricular leads $R$ and $F$, and in leads $C_{1}$ and $C F_{1}$; the comparative figures are shown in Table $I$. The amplitude of the $P$ wave was measured in the four leads to the nearest $0.5 \mathrm{~mm}$. from the top of the isoelectric line in upright waves and from the bottom in inverted waves. Though the number of cases is far too small to draw conclusions, it appears that auricular lead $F$ is not only superior to auricular lead $R$, but is also the best of the four leads for the study

TABLE I.-Size of P WAVES in VARIous LeAdS

\begin{tabular}{|c|c|c|c|c|c|c|c|c|}
\hline \multirow{2}{*}{$\begin{array}{c}\text { Case } \\
\text { Number }\end{array}$} & \multirow{2}{*}{\multicolumn{4}{|c|}{ Rhythm }} & \multicolumn{4}{|c|}{ Amplitude of $\mathbf{P}$ wave in $\mathrm{mm}$. in } \\
\hline & & & & & Auric. lead R & Auric. lead F & $\mathrm{CR}_{1}$ & $\mathrm{CF}_{1}$ \\
\hline \multirow[t]{2}{*}{$\begin{array}{l}1 \text { (Fig. 8) } \\
2 \\
3 \\
4 \\
5 \\
6 \\
7 \\
8 \text { (Fig. 9) } \\
9 \\
10\end{array}$} & $\begin{array}{l}\text { Aricular flutter ... } \\
\text { 2: } 1 \text { A-V block } . . \\
\text { Sinus rhythm .. } \\
\text { Auricular fibrillation } \\
\text { Sinus rhythm ... } \\
\text { Sinus rhythm .. } \\
\text { Auricular fibrillation } \\
\text { Sinus rhythm .. } \\
\text { Auricular fibrillation } \\
\text { Sinus rhythm ... }\end{array}$ & $\begin{array}{l}\cdots \\
\cdots \\
\cdots \\
\cdots \\
\cdots \\
\cdots \\
\cdots \\
\cdots\end{array}$ & $\begin{array}{l}\cdots \\
\cdots \\
\cdots \\
\cdots \\
\cdots \\
\cdots \\
\cdots \\
\cdots\end{array}$ & $\begin{array}{l}\cdots \\
\cdots \\
\cdots \\
\cdots \\
\cdots \\
\cdots \\
\cdots \\
\cdots\end{array}$ & $\begin{array}{l}1 \cdot 5 \\
2 \cdot 5 \\
1 \\
1 \\
2 \cdot 5 \\
2 \\
1 \\
1 \cdot 5 \\
1 \\
1\end{array}$ & $\begin{array}{l}3 \\
2 \cdot 5 \\
2 \\
2 \\
1 \\
2 \cdot 5 \\
2 \\
4 \\
1 \\
1\end{array}$ & $\begin{array}{l}1 \cdot 5 \\
2 \cdot 5 \\
1 \\
1 \\
2 \\
2 \\
1 \\
4 \\
1 \\
2\end{array}$ & $\begin{array}{l}2 \\
2 \cdot 5 \\
2 \\
1 \cdot 5 \\
1 \\
2 \cdot 5 \\
2 \\
2 \\
1 \\
1\end{array}$ \\
\hline & Mean ampl & tude & $\cdots$ & . & $1 \cdot 5$ & $2 \cdot 1$ & $1 \cdot 8$ & $1 \cdot 75$ \\
\hline
\end{tabular}


of auricular activity. On the other hand, if the exploring electrode is placed in the fourth intercostal space at the right sternal border, the results are likely to be better when the exploring electrode is paired with the right arm than when paired with the left leg. An illustrative example is shown in Fig. 9. The cardiogram was obtained from a man aged 45 years, suffering

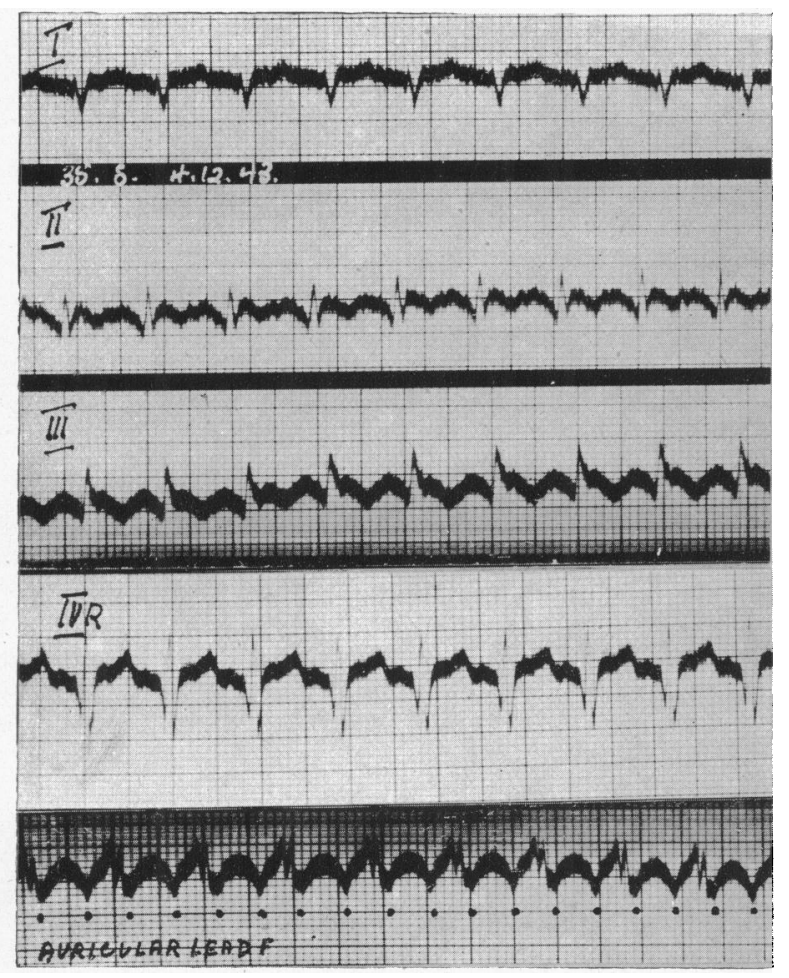

FIG. 8.-Case 7. Mitral stenosis, with $2: 1$ auricular flutter. Conspicuous flutter waves in auricular lead F.

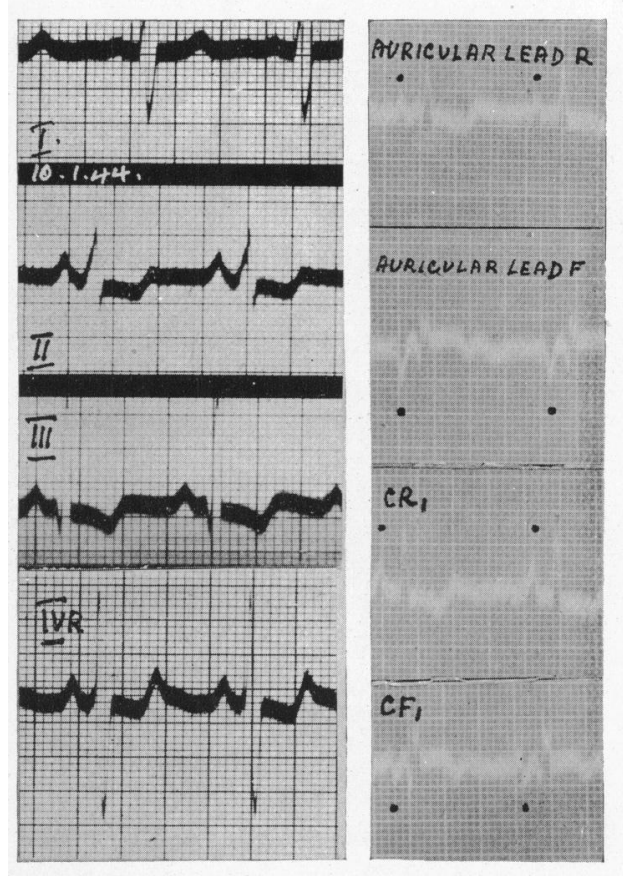

FIG. 9.-Case 8. Chronic cor pulmonale. Large auricular deflections in auricular lead $\mathrm{F}$, and in lead $\mathrm{CR}_{1}$.

from chronic cor pulmonale. The tracing shows equally large $\mathrm{P}$ waves in auricular lead $\mathrm{F}$ and in lead $C_{1}$ (inverted in the former, upright in the latter), and much smaller $\mathbf{P}$ waves in auricular lead $\mathrm{R}$ and in lead $\mathrm{CF}_{1}$. Another advantage of auricular lead $\mathrm{F}$ over lead $\mathrm{CR}_{1}$ is that the $\mathbf{P}$ wave in the former is nearly invariably opposite in direction to that in lead II. Thus, a combined analysis of these two leads is more likely than any of the standard leads to disclose a $\mathbf{P}$ wave obscured by the ventricular complex, and especially by the $\mathrm{T}$ wave, combining to simulate a split $\mathrm{T}$ wave. The practical value of this can be seen in the tracings reproduced in Fig. 1A and 5.

In many records the auricular leads failed to display larger $P$ waves than did the standard leads. It is not easy to explain this lack of uniformity. It would seem at first that the size of the right auricle is an important factor determining the amplitude of the $\mathrm{P}$ wave. Lewis (1910), in fact, found that the maximal oscillations occurred in cases of auricular fibrillation in which the right auricle was enlarged. On the other hand, Evans (1941) found that conspicuous auricular waves in lead $\mathrm{CR}_{1}$ were by no means dependent on extension of the heart to the right. Our results agree with those of Evans. We were unable to find any close correlation between the size of the right auricle and the amplitude of the $\mathrm{P}$ waves in the auricular leads. Out of the six cases of paroxysmal tachycardia with distinct $\mathbf{P}$ waves in the auricular leads, four were examined radioscopically: in none was the right auricle seen to be enlarged; in two all cardiac chambers were normal in size; the third (coronary thrombosis) had moderate enlargement of the left ventricle; and the fourth (mitral stenosis) showed slight enlargement 
of both ventricles and of the left auricle. The fifth case of paroxysmal tachycardia was too ill to be taken to the screening room; he died shortly after admission, and the autopsy revealed no cardiac enlargement. In the sixth case, there were no data available regarding the size of the heart apart from physical examination, which did not suggest cardiac enlargement. The four remaining cases of paroxysmal tachycardia with doubtful or unsuccessful auricular leads also had normal-sized right auricles: in one the heart was normal in size; in two there was slight enlargement of the left ventricle; in the fourth, which was not screened, autopsy showed only slight enlargement of the left ventricle. The patient with mitral stenosis and auricular flutter, whose cardiogram is reproduced in Fig. 8, was proved by radioscopy to have a general cardiac enlargement, including possible dilatation of the right auricle. In the cases of auricular fibrillation and sinus rhythm there was also a lack of correlation between the amplitude of the $\mathbf{P}$ wave and the size of the right auricle. It is noteworthy that in a case of mitral stenosis and auricular fibrillation with very marked enlargement of both auricles, confirmed by autopsy, the oscillations were hardly visible. On the other hand, a comparatively large $\mathbf{P}$ wave ( $3 \mathrm{~mm}$. in amplitude) was encountered in a case of coronary thrombosis (T III type) in which the autopsy showed no auricular enlargement at all. It is evident from this analysis that the size of the right auricle cannot be the only factor determining the amplitude of the $\mathbf{P}$ wave. The anatomical position of the right auricle in the thoracic cavity and its relation to the anterior chest wall are possibly important factors influencing the amplitude of the $\mathrm{P}$ wave in the auricular leads; but at present we have no confirmatory evidence in support of this suggestion.

\section{SUMMARY}

Special chest leads were used for the study of auricular activity and compared with the standard leads. The exploring electrode was placed in the third intercostal space at the right sternal border and paired with the right arm or left leg. The former lead was referred to as auricular lead R, the latter as auricular lead F. Auricular lead F was found to be more useful than auricular lead $\mathrm{R}$.

These special chest leads were studied in cases with paroxysmal tachycardia, with auricular fibrillation and flutter, and in a number with sinus rhythm. They showed auricular waves often to much better advantage than did the standard leads. It is suggested, therefore, that the recording of these leads is indicated in all cases in which there is doubt about the activity of the auricles.

No correlation was found between the size of the right auricle and the amplitude of the $P$ wave as recorded in the auricular leads. It seems, therefore, that the amplitude of the $\mathbf{P}$ wave in the auricular leads is also determined by factors other than the size of the right auricle. The anatomical position of the right auricle in the thoracic cavity and its relation to the anterior chest wall are suggested as possible factors.

I am indebted to Professor Hume for his helpful criticism and advice. I wish to thank Dr. Maurice Campbell and Dr. William Evans for their suggestions, and Dr. I. E. McCracken, Medical Officer of Health, Newcastle on Tyne, and Dr. G. P. Harlan, Medical Superintendent, Newcastle General Hospital, for facilities provided.

\section{REFERENCES}

Barker, P. S., Wilson, F. N., Johnston, F. D., and Wishart, S. W. (1943). Amer. Heart J., 25, 765.

Brown, W. H. (1936). Ibid., 12, 307.

Deglaude, L., and Laubry, P. (1939). Arch. Mal. Cour, 32, 121.

Drury, A. N., and Iliescu, C. C. (1928). Heart, 8, 171.

Evans, W. (1941). Brit. Heart J., 3, 247.

Faulkner, J. M. (1943). Quoted by Williams and Ellis.

Holzman, M. (1937). Arch. f. Kreislauff., 1, 1.

Lewis, T. (1910). Heart, 1, 306.

Lian, C., and Pinchenzon, B. (1938). Cardiologia, 2, 56.

Schoenewald, G. (1939). Middl. Hosp. J., 39, 183.

Standardization of Pracordial Leads. Memorandum by the Cardiac Society of Great Britain and Ireland and the American Heart Association (1939). Brit. Heart J., 1, 43.

Williams, C., and Ellis, L. B. (1943). Arch. intern. Med., 71, 137.

Wood, P., and Selzer, A. (1939). Brit. Heart J., 1, 49. 